\title{
Janelas Curriculares de Educação Popular na Universidade de Évora: dar utilidade social ao conhecimento académico
}

\author{
Curricular Windows of Popular Education in University of Évora: \\ Promote social utility from academic knowledge
}

Bravo Nico*, Lurdes Pratas Nico***, Antónia Tobias*, João Barnabé*,Patrícia Ramalho***, Daniela Lopes*** *Universidade Popular Túlio Espanca/Universidade de Évora/Portugal,**Direção Geral dos Estabelecimentos Escolares do Ministério da Educação e Ciência,Delegação Regional do Alentejo/Portugal, ***Escola Comunitária de São Miguel de Machede/SUÃO-Associação de Desenvolvimento Comunitário/Portugal

\begin{abstract}
Resumo
O projeto Janelas Curriculares de Educação Popular no Ensino Superior Universitário pretende proporcionar aos estudantes da Universidade de Évora - através da sua participação em projetos educativos da Universidade Popular Túlio Espanca/UPTE - oportunidades de conceber, planificar e concretizar projetos de educação não formal abertos à participação da população do Alentejo, decorrentes da mobilização do conhecimento e da competência científica, cultural, técnica e tecnológica oriundos da respetiva formação académica e enquadrados, sempre que possível, no âmbito dos planeamentos didáticos das unidades curriculares frequentadas.

Palabras clave: Educação comunitária, Educação não formal, ensino superior, estudantes, cidadania
\end{abstract}

\begin{abstract}
The Curricular Windows of Popular Education Project in Hight Education aims to give students at University of Évora - by their participation in educational projects at Tulio Espanca Popular University / UPTE - opportunities to design, plan and implement non-formal education projects that are open to the participation of the Alentejo population, in result from the mobilization of knowledge and scientific, cultural, technical and technological skills derived from the respective academic formation and integrated, whenever possible, within the framework of didactic plannings in frequented course units.

Keywords Community Education, Non-formal Education, Higher Education, students, citizenship
\end{abstract}

\section{Introdução}

O projeto Janelas Curriculares de Educação Popular no Ensino Superior Universitário pretende proporcionar aos estudantes da Universidade de Évora - através da sua participação em projetos educativos da Universidade Popular Túlio Espanca (UPTE/UÉ) - oportunidades de conceber, planificar e concretizar projetos de educação não formal (Trigo, 2002) abertos à participação da população do Alentejo, decorrentes da mobilização do conhecimento e da competência científica, cultural, técnica e tecnológica oriundos da respetiva formação académica e enquadrados, sempre que possível, no âmbito dos planeamentos didáticos das unidades curriculares frequentadas. Neste contexto, o projeto aposta em convocar as aprendizagens concretizadas no âmbito curricular das diferentes formações da Universidade de Évora para o esforço de promoção de oportunidades de aprendizagem em contextos não formais e de divulgação científica e cultural dirigidas a públicos menos frequentes no contexto universitário e, habitualmente, com níveis de escolaridade menos qualificados. Numa perspetiva inovadora, concretiza, de uma forma concomitante, a missão de qualquer universidade: a produção do conhecimento, a formação superior e o serviço à comunidade, neste caso, através de projetos de extensão educacional inscritos no conceito de Aprendizagem ao Longo da Vida (Comissão Europeia, 2000), nas diferentes áreas científicas presentes na academia. $\mathrm{O}$ presente projeto tenta, ainda, consolidar e institucionalizar esta realidade no ensino superior universitário em Portugal, assentando no pressuposto de que, em contexto curricular, é possível e qualitativamente vantajoso para a qualidade das aprendizagens, a substituição ou articulação de alguns instrumentos didáticos e de avaliação pela participação discente em projetos de divulgação e promoção científicas, nos quais, se mobilizam e aplicam, em contexto real de educação popular, os conhecimentos e as competências edificados na academia. Por outro lado, a certificação desta participação, em complementaridade com a certificação académica tradicional, diferencia o $\mathrm{CV}$ dos estudantes participantes, porque o enriquece com competências habitualmente ausentes dos currículos académicos mas valorizadas em contextos profissionais. Por último, será de salientar de que a participação de professores e estudantes no presente projeto, através da construção e concretização de janelas

Este conteúdo decorre do projeto Janelas Curriculares de Educação Popular no Ensino Superior Universitário, promovido pela Universidade Popular Túlio Espanca da Universidade de Évora e financiado pela Fundação Calouste Gulbenkian, no ámbito do Programa Gulbenkian Qualificação das Novas Gerações/Projetos de Desenvolvimento do Ensino Superior. 
curriculares de educação popular na Universidade de Évora poderá abrir uma outra dimensão na formação dos estudantes e no trabalho dos seus professores: a Solidariedade. $\mathrm{Na}$ realidade, a transferência, para a sociedade, dos conhecimentos e das capacidades construídas nas salas de aula e nos laboratórios universitários possibilitará a criação de uma diferente perceção da utilidade do conhecimento, do seu papel no exercício da cidadania e da relevância que o mesmo pode desempenhar na coesão social. Simetricamente, poderá ocorrer uma diferente leitura do trabalho educativo realizado pelas universidades, por parte dos participantes nestes projetos. O papel dos órgãos de comunicação social, nesta dimensão, será crítico, atendendo ao seu poder de divulgação junto de toda a sociedade. Através da comunicação social, a Universidade também cumpre o seu papel de Responsabilidade Social, como a instituição mais qualificada do território local e regional e como centro, por excelência, produtor e difusor do conhecimento e da cultura

\section{O Projeto}

Desde o seu nascimento, a UPTE tem desenvolvido projetos educacionais, em contexto não formal, de matriz popular e dirigidos a públicos pouco escolarizados e mais distantes, geográfica e socialmente, dos percursos e das rotinas de qualificação. No âmbito destes projetos, têm participado professores e estudantes das diferentes formações da Universidade de Évora, que, de forma voluntária, se têm empenhado na promoção de variadas atividades de divulgação cultural e científica.

O projeto Janelas Curriculares de Educação Popular no Ensino Superior Universitário, promovido pela UPTE, nasce enquadrado na missão institucional da Universidade de Évora e visando concretizar a responsabilidade social que lhe cabe assumir, na comunidade e no território em que se localiza e atua. Aliás, já em 2009, quando a academia eborense cria a Universidade Popular Túlio Espanca/UPTE (www.utulioespanca.uevora.pt), inscreve-a, nos respetivos estatutos, como "uma unidade científicopedagógica que tem por objetivos fundamentais garantir aos cidadãos oportunidades diversificadas de formação ao longo da vida, no âmbito da estratégia de entrosamento da Universidade com a sociedade envolvente". Nesta coordenada estatutária, a UPTE tem sempre assumido, como finalidade, a conceção, planificação e concretização de projetos de educação não formal, recorrendo ao potencial cultural, científico, técnico e humano da Universidade de Évora e dirigidos a toda a população do Alentejo, em parceria, privilegiada e cooperativa, com as instituições da região.

O projeto Janelas Curriculares de Educação Popular no Ensino Superior Universitário foi um dos cinco projetos apoiados e financiados, a nível nacional, em 2014, pela Fundação Calouste Gulbenkian, importante fundação portuguesa, no âmbito do Programa
Gulbenkian Qualificação das Novas Gerações/Projetos de Desenvolvimento do Ensino Superior.

\section{A linha da Educação Popular na Universidade de Évora}

Não são recentes as preocupações da Universidade de Évora e desta equipa de investigação com as questões da Educação Popular e do papel da academia nesse esforço, permanente e socialmente responsável, de criação e qualificação de oportunidades para o exercício do Direito à Educação. Exemplos dessa preocupação têm sido as sucessivas realizações do Congresso «Aprender no Alentejo», fórum regional sobre educação, no qual têm sido divulgadas centenas de experiências educacionais de todas as naturezas e contextos institucionais [Nico, B. (1996, 1999, 2001a, 2011b, 2002), Nico, L. (2011), Nico, B. \& Nico, L., 2011)].

Recentemente - na sequência de um projeto de investigação promovido pelo Centro de Investigação em Educação e Psicologia da Universidade de Évora (CIEP/UÉ), financiado pela Fundação para a Ciência e a Tecnologia (FCT), desenvolvido por uma equipa de investigação que contou com a generalidade dos membros da equipa do presente projeto (projeto "Arqueologia das Aprendizagens no concelho de Alandroal"/Ref ${ }^{\mathrm{a}} \quad$ FCT/ PTDC/CED/81388/2006, iniciado em 2 de Novembro de 2007 e concluído em 31 de Outubro de 2011 -, foi possível envolver estudantes da Universidade de Évora na promoção de algumas das atividades do Pólo de Alandroal da UPTE, entretanto criado, e que congregaram a participação de mais de 500 cidadãos daquele concelho do Alentejo (Nico, 2011; Nico et al, 2013). O mesmo aconteceu, na sede da UPTE, em Évora e nos seus Pólos de Viana do Alentejo e de Portel.

Um outro projecto de investigação mais recentemente concretizado no mesmo contexto institucional (projecto "As novas Núpcias da qualificação no Alentejo"/ref $\mathrm{f}^{\mathrm{a}}$ FCT/ PTDC/CPE-CED/104072/2008, iniciado em 1 de Junho de 2010 e concluído em 31 de Maio de 2013) proporcionou uma leitura ampla do espectro de qualificação da população alentejana que, na última década, realizou percursos não escolares de aprendizagem e os reconheceu, validou e certificou, no âmbito dos dispositivos de Educação e Formação de Adultos disponíveis. Esta informação (Nico et al, 2012), não só se revelou de grande utilidade para o desenho e concretização de novos dispositivos de educação para adultos, como permitiu, uma vez mais, relevar a importância dos contextos não formais de aprendizagem na qualificação das pessoas na região Alentejo.

\section{A dimensão pedagógica do projeto}

Partindo-se do pressuposto de que a assunção do projeto pedagógico da UPTE, por parte da academia eborense, é perspetivado como um recurso didático disponível para a valorização das aprendizagens dos estudantes e um instrumento privilegiado para a socialização do conhecimento científico e cultural produzido e ensinado na Universidade de Évora e uma excelente oportunidade de diálogo entre os saberes 
académicos e os conhecimentos experienciais [Nico, B. (2002, 2012), Nico, B. \& Costa, E. (2004), Nico, B. \& Nico, L. (2012a, 2012b)], a abordagem metodológica estruturou-se, de acordo com o seguinte esquema:

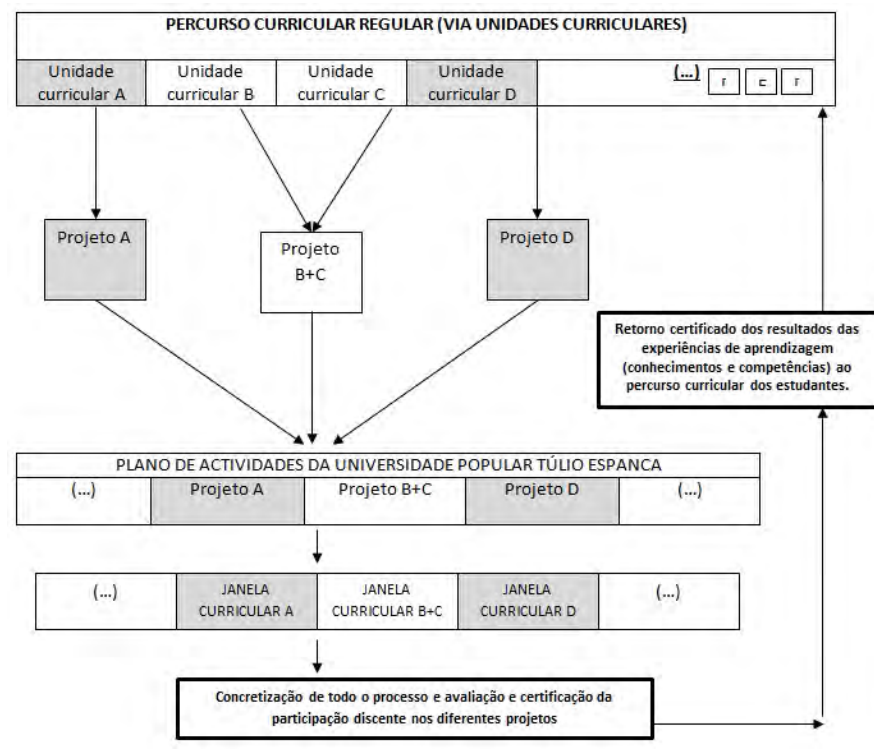

Figura 1. Esquema Geral do Projeto

Para concretizar o projeto, estabeleceram-se os seguintes passos gerais:

I. apresentar, aos docentes e discentes da Universidade de Évora, a possibilidade de implementarem Janelas Curriculares de Educação Popular, no âmbito dos planos de estudo das unidades curriculares, como alternativa e/ou complemento didático;

II. elaborar, no âmbito da UPTE, projetos de educação popular visando a promoção da literacia científica e cultural e destinados a públicos diversificados;

III. estabelecer parcerias com instituições locais e regionais, tendo em vista a concretização dos projetos de educação popular em diferentes contextos geográficos e para diferentes públicos;

IV. mobilizar a comunicação social local e regional (órgãos de comunicação social do grupo Diário do SUL) para a divulgação da iniciativa e para a socialização dos projetos;

V. recorrer às Tecnologias da Informação e da Comunicação, para aumentar a abrangência e os destinatários dos projetos de educação popular.

Dos passos gerais apresentados, distinguem-se vários tipos de janelas curriculares que passamos a apresentar:

Categoria A: Janela curricular que aglomera um fluxo de várias janelas e prevê uma atividade conjunta de diferentes atores, com vista a garantir aos cidadãos oportunidades de formação ao longo da vida, promovendo o entrosamento da Universidade com a sociedade envolvente.

Categoria B: Janela Curricular que implica o desenvolvimento de projetos promovidos por estudantes, avaliados pela sua atividade no âmbito de uma ou mais unidade curriculares.
Categoria C: Participação pontual de pessoal técnico, funcionários, estudantes e docentes da Universidade no desenvolvimento de projetos comunitários. Esta participação, no caso de serem estudantes, não será avaliada no âmbito de Unidades Curriculares.

Categoria D: Momentos de partilha e desenvolvimento de projetos com determinados agentes da sociedade civil, designadamente membros de associações, corporações, escolas, parceiros, etc.

\section{A rede de parceiros}

A rede inicial de parceiros contou com a participação do grupo de comunicação social Diário do SUL (www.diariodosul.com.pt) e da Escola Comunitária de São Miguel de Machede/SUÃO-Associação de Desenvolvimento Comunitário (www.suao.pt). No entanto, assumiu-se, desde a primeira hora, a necessidade de se virem a estabelecer novas parcerias institucionais que decorressem, naturalmente, da dinâmica do projeto Janelas Curriculares e da participação dos estudantes oriundos dos diferentes locais do Alentejo. Assim, será natural que sejam celebrados protocolos com autarquias locais, organizações não governamentais, instituições de natureza comunitária e social e empresas. $\mathrm{O}$ perímetro geográfico destas parcerias não se circunscreve à cidade de Évora, sendo que o próprio território se assume como contexto formador [Nico, (2013). Nico, B. \& Nico. L. (2011)] e, consequentemente, como recurso curricular (Nico, B. \& D’Orey, 2004).

\section{Janelas Curriculares realizadas}

\section{Visita de Estudo à Universidade de Évora}

Os alunos da unidade curricular Projetos de Intervenção em Educação e Educação de Adultos procederam a um levantamento de necessidades e preparação de uma iniciativa. A partir de instrumentos de recolha de dados com recurso a entrevista semi-estruturada - construída e validada para o efeito (Bodgan \& Biklen, 1994) -, resultaram algumas pistas de projetos a desenvolver, tendo, por público beneficiário, a população do Bairro de Almeirim e São Miguel de Machede.

Assim, realizou-se, no dia 18 de Abril de 2015, uma primeira Visita de Estudo à Universidade de Évora, que envolveu a participação de indivíduos do Bairro de Almeirim e da vila de São Miguel de Machede, estudantes de Educação de Adultos, participantes e cooperantes da iniciativa, docentes e investigadores da Universidade de Évora. A janela curricular' compreendeu a realização de uma sessão de preparação da visita de estudo. As ações integradas neste projeto projetaram o conhecimento académico para fora dos muros da academia, propiciando novas aprendizagens à comunidade e disponibilizando aos estudantes, docentes da Universidade de Évora a oportunidade de socializarem o seu conhecimento académico.

\section{Visita de Estudo a Campo Maior}

No início, os alunos da unidade curricular Projetos de Intervenção em Educação procederam a um 
levantamento de necessidades junto da população residente no Bairro de Almeirim. Desse trabalho, desenvolvido a partir do instrumento de recolha de dados entrevista semi-estruturada - construída e validada para o efeito (Bodgan \& Biklen, 1994) -, resultaram algumas pistas de projetos a desenvolver, tendo por público beneficiário, a população do Bairro de Almeirim e de São Miguel de Machede.

Assim, realizou-se no dia 14 de Junho de 2015, uma Visita de Estudo a Campo Maior, que envolveu a participação de indivíduos dos Bairros de Almeirim e dos Canaviais, da vila de São Miguel de Machede, da população da cidade de Évora e estudantes, docentes e investigadores da Universidade de Évora. A janela Curricular compreendeu, a realização de duas sessões de preparação da visita de estudo a Campo Maior que contaram com o envolvimento de docentes voluntários de diversos domínios científicos da Universidade de Évora e o contributo da Associação de Moradores do Bairro de Almeirim, da Escola Comunitária de São Miguel de Machede e da Junta de Freguesia dos Canaviais. Este recente projeto, além de contar com a participação de estudantes e docentes do Curso de Licenciatura em Ciências da Educação, envolveu estudantes e docentes de outras áreas científicas:

- Professora do Departamento de Química (contributo com uma intervenção acerca do processo químico de descafeinação do café, relacionando esse aspeto com a visita ao Centro de Ciência do Café/Empresa Delta, em campo Maior);

- Professora do Departamento de Biologia e Estudante, da Licenciatura em Agronomia (contributo com uma intervenção acerca do processo bioquímico de aromatização do azeite, com recurso a ervas aromáticas, relacionando tal com a Visita ao Museu do Lagar de Campo Maior;

- Estudante do Curso de Mestrado em Arqueologia e Ambiente (contributo com uma intervenção acerca das lendas relacionadas com a origem do nome de Campo Maior e da Ribeira de Enxara).

\section{Conclusões}

O projeto Janelas Curriculares de Educação Popular no Ensino Superior Universitário encontra-se, ainda, em execução, pelo que ainda não existem resultados finais que permitam avaliar do nível de consecução do mesmo. No entanto, o balanço realizado pela equipa de investigação, nos diversos relatórios intercalares que tem produzido, evidencia alguma dificuldade de adesão por parte dos docentes e investigadores da academia eborense e, em consequência, dos seus estudantes. A área científica e de formação em que esta dificuldade é menos evidente é a das Ciências da Educação, por razões de óbvia proximidade com o território científico do projeto. Por outro lado, a adesão das instituições locais tem sido boa, e tem-se traduzido no estabelecimento de, fáceis e dinâmicos, processos de cooperação que têm criado verdadeiras oportunidades de «diálogo» entre a academia e o território.

\section{Referências bibliográficas}

Bogdan, R. \& Biklen, S. (1994). Investigação qualitativa em educação. Porto: Porto Editora.

Comissão Europeia (2000). Memorando sobre Aprendizagem ao Longo da Vida. Bruxelas.

Nico, B. \& Nico, L. (Orgs.) (2011). Qualificação de Adultos: realidades e desafios no Sul de Portugal. Colecção Educação, Território e Desenvolvimento Local. N. ${ }^{\circ}$ 2. Mangualde: Edições Pedago (http://hdl.handle.net/10174/2864)

Nico, B. \& Costa, E. (2004). "A experiência da formação conjunta: um exemplo de gestão curricular no âmbito da formação de professores da Universidade de Évora". in Infância e Educação - Investigação e Práticas. nº 6 (Jan). pp. 145-149

Nico, B. \& D’orey, J. (2004). “Gestão Curricular Local: fundamento para a promoção da literacia científica". in Bravo Nico et al (Orgs). Aprender no Alentejo - II Encontro Regional de Educação. Évora: Departamento de Pedagogia e Educação da Universidade de Évora, pp. 111-115

Nico, B. \& Nico, L. (2012a). “O Território na base da construção de um projecto de inovação científica $e$ pedagógica na Universidade de Évora”. in L. Bermúdez \& I. Álvarez (Comp.). FECIES 2012. Santiago de Compostela: Asociación Española de Psicología Conductual. pp. 113- 117 http://hdl.handle.net/10174/8584

Nico, B. \& Nico, L. (2012b). Offical Discourses in Educational Systems. Competences. The New Curriculum Password?. In J. Paraskeva e J. Torres Santome (Eds.) Globalisms and Power. Iberian Educational and Curriculum Policies. New York: Peter Lang, pp., 133 - 142

Nico, B. (1996). “A identidade vocacional em alunos universitários: um estudo de caso". in Estrela, A. et al (orgs.). Formação, Saberes Profissionais e Situações de Trabalho - Actas do VI Colóquio Nacional da AIPELF/AFIRSE. Lisboa: Universidade de Lisboa. pp. 105-116

Nico, B. (1999). “Currículo e conforto académico na Universidade". in Tavares, J. et al (orgs.). Investigar e Formar em Educação - Actas do IV Congresso da SPCE. Porto: SPCE.pp.349-354

Nico, B. (2001a). A adaptação do(a) estudante à universidade: porque não também o contrário? In Sousa, B.R. et al (Orgs.), III Simpósio - Pedagogia na Universidade. Lisboa: UTL. pp. 55-63

Nico, B. (2001b). Tornar-se Estudante Universitário: contributo do Conforto Académico na definição de uma estratégia curricular de sucesso (tese de doutoramento, policopiada). Évora: Universidade de Évora

Nico, B. (2002), "O Meio Periescolar: uma variável do currículo universitário do(a) caloiro(a)?”. in Bruno Sousa et al (Orgs.). III Simpósio «Pedagogia na Universidade», Lisboa: Universidade Técnica de Lisboa, pp. 263-266

Nico, B. (2012). "Saberes, linguagens e práticas educativas: os vértices de um diálogo necessário (o caso do Alandroal/Portugal)". In Mairce Araújo e Jacqueline Morais (Orgs.). Vozes da Educação: 
formação de professores, narrativas, políticas e memórias. Rio de Janeiro: Editora da Universidade do Estado do Rio de Janeiro. pp: 99-110 (http://hdl.handle.net/10174/2862)

Nico, B.(2013). "Passado e Futuro no Presente dos Percursos de Qualificação: A Equação da Aprendizagem”. in II International Conference Learning and Teaching in Higher Education/ Learning Orchestration in Higher Education. Évora: Universidade de Évora (http://hdl.handle.net/10174/8582)

Nico, B. (Coord.) (2011). Arqueologia das Aprendizagens em Alandroal. Mangualde: Edições Pedago (http://hdl.handle.net/10174/2894)

Nico, B. (Coord.), Nico, L., Tobias, A., Valadas, F. \& Ferreira, F. (Orgs.) (2013). Atlas da Educação em Alandroal. Mangualde: Edições Pedago e Universidade de Évora (http://hdl.handle.net/10174/8610)
Nico, B., Nico, L., Ferreira, F. \& Tobias, A. (2012). "O Projecto As Novas núpcias da Qualificação no Alentejo: os impactos da qualificação nas pessoas e nos territórios". in L. Bermúdez \& I. Álvarez (Comp.). FECIES 2012. Santiago de Compostela: Asociación Espanõla de Psicologia Conductual.pp.136-14 (http://hdl.handle.net/10174/7987)

Nico, L. (2011). A Escola da Vida: reconhecimento e validação de adquiridos experienciais em Portugal (fragmentos de uma década). Mangualde: Edicões Pedago (http://hdl.handle.net/10174/5075)

Trigo, M.(2002). "Importância das aprendizagens não formais e informais na formação dos adultos". In Revista saber Mais. N. ${ }^{\circ}$ 12. Lisboa: ANEFA. pp.18-20. 